\title{
RÜCKBLICK
}

\section{Neujahrsempfang in Hamburg}

Das Jahr beginnt mit Neujahrsempfängen - in Hamburg unter anderem mit dem der immobilienwirtschaftlichen Verbände. Einer der Veranstalter ist der DVAG, und so begrüßte in diesem Jahr der DVAG-Vorsitzende, Jan Kotonski, die Besucher, die in den Wintergarten der DZ HYP gekommen waren (s. STANDORT-Gespräch). Als Hauptredner war Prof. Dr. Hans-Werner Sinn eingeladen, der frühere Präsident des Münchner ifo-Instituts, der über die wirtschaftlichen Perspektiven von Europa, Nordamerika und China referierte und ein eher skeptisches Fazit zog: Wenn drei Risiken zusammenkämen, der US-Präsident Trump, der Brexit und Italien (auf dessen Wirtschafts- und Finanzpolitik er zuvor eingegangen war), falle es schwer, für 2019 noch optimistisch zu sein, so Sinn. Dr. Georg Reutter, der Vorstandsvorsitzende der DZ HYP und Gastgeber des Abends, eröffnete gleichwohl das Buffet und läutete damit ein fröhliches Get together ein.

Heiner Schote

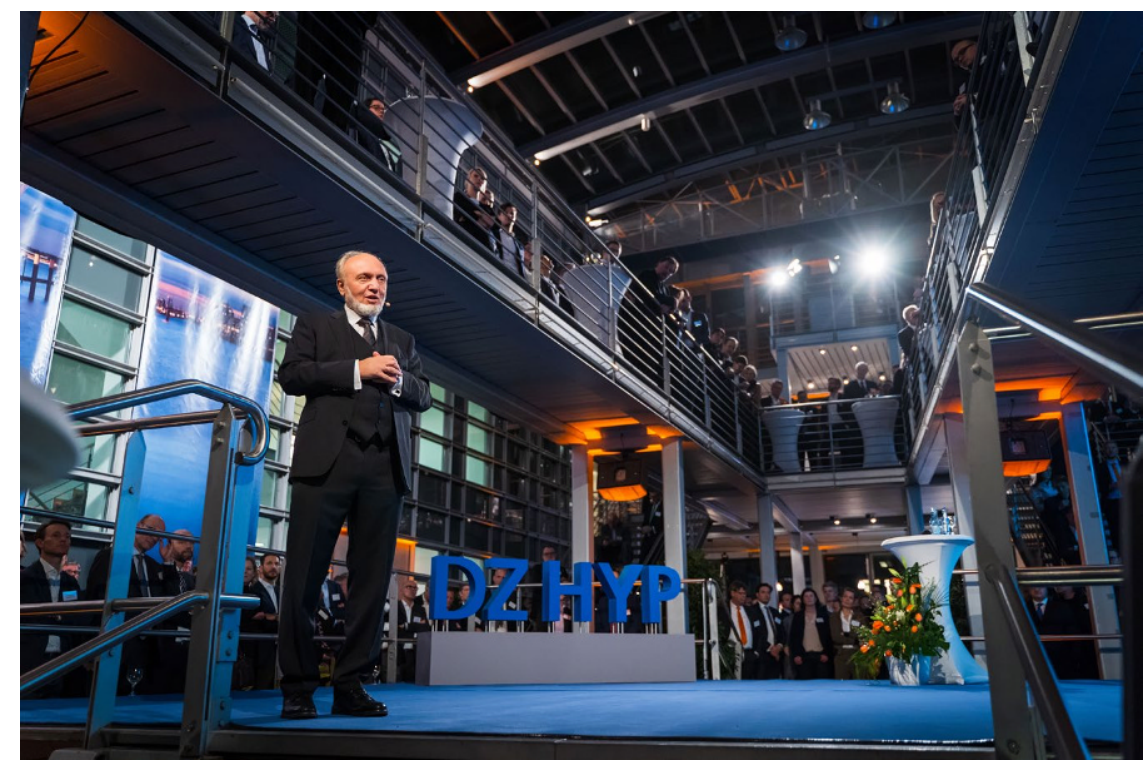

Gastredner Prof. Dr. Hans-Werner Sinn im Dachgeschoss der DZ Hyp. (Foto: DZ Hyp)

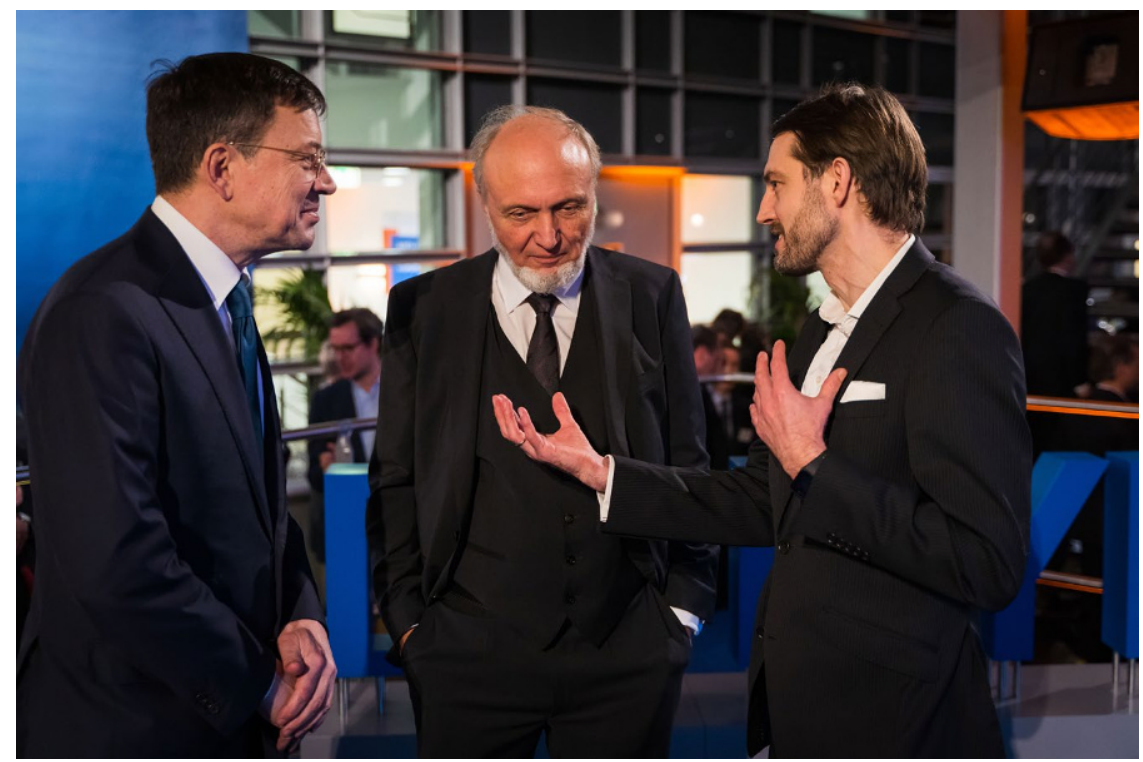

Im Gespräch: Dr. Georg Reutter, DZ Hyp, Prof. Dr. Hans-Werner Sinn, eh. Leiter des ifo-Institut, und Jan Kotonski, DVAG-Vorsitzender. (Foto: DZ Hyp) 